\title{
Role of Religious Beliefs and Practices on the Mental Health of Athletes with Anterior Cruciate Ligament Injury
}

\author{
Amira Najah1,2,3, Abdulaziz Farooq1, Riadh Ben Rejeb² \\ ${ }^{1}$ Aspetar, Orthopaedic and Sports Medicine Hospital, Doha, Qatar \\ ${ }^{2}$ Psychology Department, Faculty of Humanities, Tunis, Tunisia \\ ${ }^{3}$ Institute of Nursing Sciences, Tunis, Tunisia \\ Email: amiranejah@yahoo.fr
}

How to cite this paper: Najah, A., Farooq, A., \& Rejeb, R. B. (2017). Role of Religious Beliefs and Practices on the Mental Health of Athletes with Anterior Cruciate Ligament Injury. Advances in Physical Education, 7, 181-190.

https://doi.org/10.4236/ape.2017.72016

Received: March 15, 2017

Accepted: May 19, 2017

Published: May 22, 2017

Copyright $\odot 2017$ by authors and Scientific Research Publishing Inc. This work is licensed under the Creative Commons Attribution International License (CC BY 4.0).

http://creativecommons.org/licenses/by/4.0/

\begin{abstract}
The present study examined the effects of religion and spirituality practices and beliefs on emotional and psychological outcomes among professional athlete with anterior cruciate ligaments (ACL) injury. Methods: A sample of professional athletes $(n=50)$ with ACL injury and prior to surgery participated in this study. Participants completed Brief Cope Inventory (BCI) and Depression Anxiety \& Stress Scale (DASS 21). From the responses to specific items related to religion and spirituality, participants were classified as high or low in religious/spiritual belief $\left(\mathrm{RS}^{\mathrm{H}}\right.$ or $\mathrm{RS}^{\mathrm{L}}$ respectively); and as high and low in their praying/meditation practice $\left(\mathrm{PM}^{\mathrm{H}}\right.$ or $\mathrm{PM}^{\mathrm{L}}$ respectively). Results: $\mathrm{RS}^{\mathrm{H}}$ participants reported better scores on overall coping $8.3 \pm 11.4$, acceptance $6.7 \pm 1.7$, self-distraction $6.2 \pm 1.8$, use of emotional support $6.9 \pm 1.5$. Reduced depression $10.6 \pm 13.0$, anxiety $14.0 \pm 18.6$ and stress $8.6 \pm 14.2$ compared to $\mathrm{RS}^{\mathrm{L}}(\mathrm{p} \leq 0.05) . \mathrm{PM}^{\mathrm{H}}$ group had better scores on overall coping $84.0 \pm$ 11.8 and use of emotional support $6.9 \pm 1.6$ compared to $\mathrm{PM}^{\mathrm{L}} \mathrm{P}=0.004$ and $\mathrm{P}=0.007$ respectively. Conclusion: The results of this study suggest that belief and practice of religion/spirituality play a central role in the processes of reconstructing the coping strategies and reducing depression, anxiety and stress.
\end{abstract}

\section{Keywords}

Religion, Spiritualty, Coping, Depression, Anxiety, Stress, Anterior Cruciate Ligament, Athlete

\section{Introduction}

The consciousness of religion and spirituality as topics demanding psychological 
attention appeared predominantly towards the latter end of the 20th century in line with the focus towards positive psychology (Sarkar et al., 2015). A number of prominent psychology scholars were keenly interested in the relationship between psychology, religion, and spirituality and they have been found that religion and spirituality may provide people with greater psychological resilience in the face of daily stressors (Perez et al., 2007). Unfortunately few studies within the sport psychology literature have directly examined the association between religion, spirituality, and well-being in sport (Sarkar et al., 2015) and more specifically in sport injuries such as Anterior Cruciate ligament. Anterior cruciate ligament sprain or tear is one of the most common knee injuries. Despite the extensive researches related to the medical and physical aspects following ACL reconstruction, in certain conditions, the normalized objective of knee status do not correspond to the capacity to perform the sport, specifically when psychological rebound is not attained (Ardern et al., 2016). Psychological variables have been significantly associated with various aspects of ACL reconstruction recovery. Despite the knowledgeable discussions related to the physical aspects preceding and/or following ACL reconstruction, only limited attention has been paid to the psychological components associated with pre-surgery. How an athlete deals with ACL injury and the decision of surgery can have tragic consequences for their return to play. The mind state of an injured athlete prior to surgery has proven to be a game-changer when it comes to the athlete's approach to surgery, pain management, and the rehabilitation process. Surgery can be enormously stressful, especially when the reduction in physical capabilities has been associated with the identity crisis (Granito, 2001). Equally, surgery has been associated with fear of dying, anesthesia, and pain (Garbee \& Gentry, 2001). Selection of an appropriate treatment strategy requires a wide range of psychological assessments along with consideration of factors such as readiness to undergo surgery, desire to return to the sport, willingness to complete treatment, and expectations regarding postoperative knee function (Everhart et al., 2013).

Many athletes who have suffered an injury report using religion, spirituality practices or beliefs as a means to cope with the stress associated with the risk to quit playing. It is evident that there has been increasing focus given to the relationship between religion indices and mental health during the past twenty years. A human's world conviction helps to figure a meaning of his painful experience (Faria, 1997). Generally, patients put their suffering into spiritual and religious frameworks for both physical and for mental illness. For many patients, religion plays a predominant role in their lives and may help them cope with their symptoms (Saad \& de Medeiros, 2012). By now, several thousand studies have been conducted demonstrating positive associations between both variables (Koenig et al., 2001). Religion and spirituality have shown a strong association with effective outcomes through mechanisms which integrate increased acceptance and social support (Ellison, Boardman, Williams, \& Jackson, 2001; Ellison \& George, 1994; George, Ellison, \& Larson, 2002). 
Simultaneously, the interaction between sport and religion has been an area of study for researchers, who have recognized the importance of religion and spirituality in athletes' lives (Coakley \& Donnelly, 2003; Hoffman, 1992; Stevenson, 1991). Coakley \& Donnelly (2003) has configured six possible reasons why athletes utilize religion; to face uncertain stressors, to do help live a morally sound life; to sanctify commitment in sport; to put sport into perspective, to create strong team cohesion and finally to maintain a certain social control. Joseph (2012) explored the concepts of "religion" and "sport" and proposed a critical perspective into their history, relationship and common aspects of development. Likewise, Jona \& Okou (2013) looked at sport and religion as essential tools for development and put forward a number of modern parallels between the two concepts. The two authors explained that athletes and coaches may use religion as psychological support tool as they face stressors and challenges in competition. They may also use aspects of religious practice to produce team cohesion (Lane, 2014).

Several reviews have been published concerning the relationship between religiosity and mental health. Some have been general in nature, while others have focused on one specific type of religiosity (Hackney \& Sanders, 2003). Research among Anterior Cruciate Ligament (ACL) injured athletes is very sparse and rare. In addition, there has been unique but recent work on Islam confirming that those who are spiritual and/or religious indicate better outcomes of mental health (Abu-Rayya et al., 2009). Future studies on Muslim population require looking at elements accounting for these associations and need to be responsive to cultural and theological matters in their assessment.

Besides, the benefits of religious and/or spirituality involvement for both mental and physical health are well documented, its function as a resource for coping is still less well known (Krägeloh, 2011). General coping theorists and researchers unrecognized the religious dimension, for the most part; Faria (1997) developed a theory of religious coping. He defined religious coping as efforts to understand and deal with life stressors in ways related to the sacred. This perspective proposes that religious coping may lead to better health outcomes by limiting potentially negative risk-related behaviors.

Studying the connections between religion, spirituality and sports injury is a challenge. The use of religion coping when injured is one area of research that has begun to receive particular attention and will be the focus of this paper. The main purpose of the current study is to confirm that belief and practice of religion/spirituality play a central role in the processes of reconstructing the coping strategies and reducing depression, anxiety and stress. In this domain, research among ACL injured athletes is very sparse. Until recently, only limited attention has been paid to the religious components associated with the pre-surgery phase. Although no formal standard exists in the scientific literature, there is growing acknowledgment of the important elements to be addressed and the appropriate means for collecting the necessary information to determine the impact of religion and/or spirituality on the coping attributes and emotional responses of injured athletes undergoing ACL reconstruction surgery. 


\section{Material and Methods}

This study was part of a larger research program investigating selected coping resources and emotional adjustments strategies among injured athletes prior to undergoing an ACL surgery.

\subsection{Participants}

Fifty professional male athletes with ACL injury undergoing ACL reconstruction surgery, who ranged in age from 18 to 30 years, were involved in the study.

\subsection{Measures}

The self-reported questionnaires assessed the injured athletes' positive and negative psychological health aspects (coping resources, depression, anxiety and stress,) using two scales. Brief Cope Inventory (BCI) Arabic version (Nawel \& Elizabeth, 2015). BCI is the abbreviated version of the original 60-item COPE Inventory. The test consists of 28 items, classified into 14 subscales: self-blame, self-distraction, active coping, denial, substance use, use of emotional support, use of instrumental support, behavioral disengagement, venting, positive reframing, planning, humor, acceptance, and religion. Items were answered on a 4-point Likert-type scale, ranging from 1 ("I have not used this at all") to 4 (I have used it a lot") (Carver, 1997). Factor analysis with Varimax rotation revealed that the translated and adapted scale has satisfactory psychometric qualities. The internal consistency of the 14 dimensions assessed by Cronbach's alpha coefficient was between $\alpha=.63$ and $\alpha=.94$. Expected divergent validity results suggested good construct validity (Nawel \& Elizabeth, 2015).

Depression Anxiety \& Stress Scale (DASS 21), in its Arabic version. DASS 21 is a short form DASS which is a self-report 4 point Likert scale and composed of three subscales: Depression (DASS-D), Anxiety (DASS-A), and Stress (DASS-S). Each item is scored from 0 (did not apply to me at all over the last week) to 3 (applied to me very much or most of the time over the past week). The alpha reliability coefficients for the DASS-21 subscales have been examined in clinical and nonclinical samples and reported as .94 for DASS-D, .87 for DASS-A, and .91 for DASS-S. (Antony et al., 1998). This scale was psychometrically validated by Taouk et al. (2001).

\subsection{Procedures}

Testing took place during the pre-admission consultation. Participants signed a consent form and were free to withdraw their participation at any stage. Data would be considered confidentially and strictly used for research purposes only. The participants completed the Brief Cope Inventory (BCI) (Carver, 1997) and the Depression Anxiety Stress Scales (DASS 21) (Brown et al., 1997). The total duration of interviews was 15 to 20 minutes.

\subsection{Statistical Procedures}

The IBM Statistical software SPSS Statistics 21.0 was used for the data analysis. 
Descriptive statistics (mean and standard deviation) were presented. The Independent Samples $t$-test was used to compares the mean coping resources and negative emotions scores of $\mathrm{RS}\left(\mathrm{RS}^{\mathrm{H}}\right.$ and $\left.\mathrm{RS}^{\mathrm{L}}\right)$ and $\mathrm{PM}\left(\mathrm{PM}^{\mathrm{H}}\right.$ and $\left.\mathrm{PM}^{\mathrm{L}}\right)$. The DASS and BCI and the Depression Anxiety \& Stress items were compared against religious/spirituality item and praying/meditating item using Spearman's Correlation. For all statistical analyses, $p \leq 0.05$ was adopted as the significance level and $N S$ corresponded to no significance.

\section{Results}

All correlations coefficients of RS and PM with BCI and DASS 21 subscales are shown in Table 1. Religious/spiritual belief scores were positively correlated with use of emotional support $(\mathrm{r}=.39, p=.006)$ and acceptance $(\mathrm{r}=.33, p=.019)$. It was negatively correlated with depression $(\mathrm{r}=-.43, p=.002)$, anxiety $(\mathrm{r}=-.42$, $p=.003)$ and stress $(\mathrm{r}=-.41, p=.004)$ from DASS. Praying/mediation practice scores were positively correlated with use of emotional support $(\mathrm{r}=.36, p=.011)$ and instrumental support $(\mathrm{r}=.34, p=.016)$ and negatively correlated with depression $(\mathrm{r}=-.31, p=.029)$, anxiety $(\mathrm{r}=-.30, p=.038)$ and stress $(\mathrm{r}=-.28$, $p=.049)$.

Table 2 shows the differences between groups for RS and PM categories. $\mathrm{RS}^{\mathrm{H}}$ group had higher overall coping $84.3 \pm 11.4$ compared to $\mathrm{RS}^{\mathrm{L}} 71.6 \pm 14.6, p=$ 0.002 . $\mathrm{PM}^{\mathrm{H}}$ group had higher overall coping $84 \pm 11.8$ compared to $\mathrm{PM}^{\mathrm{L}} 73.6 \pm$ 14.3, $p=0.004$. ${ }^{\mathrm{H}}$ group had better scores on self-distraction $6.2 \pm 1.8$ compared to $\mathrm{RS}^{\mathrm{L}} 5.1 \pm 1.7, p=0.037$. The $\mathrm{RS}^{\mathrm{H}}$ group had significantly better scores on Self-distraction, use of emotional support, and acceptance compared to $\mathrm{RS}^{\mathrm{L}}(p \leq$

Table 1. Correlations (Person correlation) between religion/spiritual belief (RS), Praying/Mediation (PM) and the BCI-DASS 21 Subscales $(n=50)$.

\begin{tabular}{ccc}
\hline & Religion/Spiritual belief & Praying/Mediation \\
\hline Self-blame & -.03 & -.07 \\
Self-distraction & .25 & .17 \\
Active coping & .26 & .11 \\
Denial & -.01 & .05 \\
Substance use & .09 & .16 \\
Use of emotional support & $.39^{* *}$ & $.36^{*}$ \\
Use of instrumental support, & .27 & $.34^{*}$ \\
Behavioral disengagement & .00 & -.04 \\
Venting & .16 & .19 \\
Positive reframing & .21 & .14 \\
Planning & .23 & .20 \\
Humor & .20 & .18 \\
Acceptance & $.33^{*}$ & .25 \\
Depression & $-.43^{* *}$ & $-.31^{*}$ \\
Anxiety & $-.42^{* *}$ & $-.30^{*}$ \\
Stress & $-.41^{* *}$ & $-.28^{*}$ \\
\hline
\end{tabular}

${ }^{\star} p<.05,{ }^{* *} p<.01,{ }^{* * *} p<.001$. 
0.037). Moreover, the $\mathrm{RS}^{\mathrm{L}}$ group had higher depression anxiety and stress scores compared to $\mathrm{RS}^{\mathrm{H}}(p \leq 0.007)$. With regards to $\mathrm{PM}^{\mathrm{H}}$ was also associated with higher use of emotional support compared to $\mathrm{PM}^{\mathrm{L}}$. No significant differences were found between the two groups $\mathrm{PM}^{\mathrm{H}}$ and $\mathrm{PM}^{\mathrm{L}}$ in depression, anxiety and stress (Table 2).

\section{Discussion}

The purpose of the study was to investigate the relationship and effects of the two aspects of religion and/or spirituality (belief and practice) on coping and emotional outcomes among professional athletes with ACL injury prior to surgery. In this cohort of athletes, the results confirmed that religion and/or spirituality have a positive role in enhancing adaptive coping and minimizing negative emotions of athletes with career-threatening injury like ACL-tear.

The results show that during the pre-surgery stage, ACL injured athletes with $\mathrm{RS}^{\mathrm{H}}$ and/or $\mathrm{PM}^{\mathrm{H}}$ exhibited the higher overall coping, acceptance, use of emotional support, and self-distraction when compared with $\mathrm{RS}^{\mathrm{L}}$ and/or $\mathrm{PM}{ }^{\mathrm{L}}$. ACL injured athletes with $\mathrm{RS}^{\mathrm{H}}$ compared to the other group scored the lower scores on item related to depression, anxiety and stress. These findings were consistent

Table 2. Brief Coping Inventory (BCI) and Depression Anxiety and Stress Scale (DASS21) subscales (Mean \pm SD) based on athlete's religion/spiritual belief (RS), Praying/Mediation (PM).

\begin{tabular}{|c|c|c|c|c|c|c|}
\hline \multirow{3}{*}{ BCI Subscales } & $\mathrm{RS}^{\mathrm{H}}$ & $\mathrm{RS}^{\mathrm{L}}$ & \multirow{3}{*}{$\mathrm{p}$-value } & $\mathrm{PM}^{\mathrm{H}}$ & $\mathrm{PM}^{\mathrm{L}}$ & \multirow{3}{*}{$p$-value } \\
\hline & $(\mathrm{n}=29)$ & $(\mathrm{n}=21)$ & & $(\mathrm{n}=24)$ & $(\mathrm{n}=26)$ & \\
\hline & $\mathrm{M} \pm \mathrm{SD}$ & $\mathrm{M} \pm \mathrm{SD}$ & & $\mathrm{M} \pm \mathrm{SD}$ & $\mathrm{M} \pm \mathrm{SD}$ & \\
\hline $\begin{array}{c}\text { Brief Coping Inventory } \\
\text { Overall }\end{array}$ & $84.3 \pm 11.4$ & $71.6 \pm 14.6$ & .001 & $84.8 \pm 11.8$ & $73.6 \pm 14.3$ & .004 \\
\hline Self-blame & $4.2 \pm 2.2$ & $4.1 \pm 2.1$ & .843 & $4.1 \pm 2.2$ & $4.1 \pm 2.2$ & .988 \\
\hline Self-distraction & $6.2 \pm 1.8$ & $5.1 \pm 1.7$ & .037 & $6.1 \pm 1.9$ & $5.5 \pm 1.8$ & .211 \\
\hline Active coping & $6.5 \pm 1.8$ & $5.7 \pm 1.9$ & .130 & $6.4 \pm 1.6$ & $5.9 \pm 2.1$ & .321 \\
\hline Denial & $3.7 \pm 2.2$ & $4.0 \pm 2.0$ & .708 & $3.8 \pm 2.1$ & $3.8 \pm 2.1$ & .966 \\
\hline Substance use & $2.6 \pm 1.0$ & $2.2 \pm 0.5$ & .167 & $2.5 \pm 1.0$ & $2.3 \pm 0.7$ & .347 \\
\hline Use of emotional support & $6.9 \pm 1.5$ & $5.1 \pm 2.2$ & .004 & $6.9 \pm 1.6$ & $5.4 \pm 2.1$ & .007 \\
\hline $\begin{array}{l}\text { Use of instrumental } \\
\text { support }\end{array}$ & $6.5 \pm 1.8$ & $5.4 \pm 1.9$ & .055 & $6.6 \pm 1.8$ & $5.5 \pm 1.9$ & .054 \\
\hline Behavioral disengagement & $3.3 \pm 1.6$ & $3.4 \pm 1.3$ & .848 & $3.2 \pm 1.4$ & $3.5 \pm 1.6$ & .442 \\
\hline Venting & $5.0 \pm 2.1$ & $4.2 \pm 1.6$ & .155 & $5.0 \pm 1.9$ & $4.3 \pm 1.9$ & .151 \\
\hline Positive reframing & $5.3 \pm 2.4$ & $5.0 \pm 2.3$ & .598 & $5.4 \pm 2.4$ & $5.0 \pm 2.3$ & .537 \\
\hline Planning & $6.6 \pm 1.3$ & $5.7 \pm 2.0$ & .102 & $6.6 \pm 1.2$ & $5.8 \pm 1.9$ & .076 \\
\hline Humor & $4.7 \pm 2.2$ & $4.0 \pm 2.4$ & .330 & $4.8 \pm 2.4$ & $4.0 \pm 2.2$ & .278 \\
\hline Acceptance & $6.7 \pm 1.7$ & $5.52 \pm 2.1$ & .029 & $6.7 \pm 1.8$ & $5.8 \pm 2.0$ & .119 \\
\hline Depression & $10.6 \pm 13.0$ & $24.7 \pm 19.5$ & .007 & $11.8 \pm 13.8$ & $20.9 \pm 19.2$ & .062 \\
\hline Anxiety & $14.0 \pm 18.6$ & $31.1 \pm 25.2$ & .013 & $15.8 \pm 19.8$ & $26.1 \pm 24.9$ & .116 \\
\hline Stress & $8.6 \pm 14.2$ & $22.4 \pm 19.00$ & .008 & $10.0 \pm 15.3$ & $18.5 \pm 18.9$ & .087 \\
\hline
\end{tabular}


with other investigations (Williams \& Sternthal, 2007; Smith, McCullough, \& Poll, 2003; Joshi, Kumari, \& Jain, 2008). The greater the level of belief, the more ACL injured athlete cope using emotional support and acceptance and the less they are likely to be depressed, anxious and/or stressed. The greater the degree of practice or meditation, the more ACL injured athlete cope using emotional and instrumental supports and the less they are likely to be depressed, anxious and or stressed.

ACL injured athletes with $\mathrm{RS}^{\mathrm{H}}$ were more distinguished in term of variables related to the capacity to overcome negative emotions and cope adaptively. Sports injury is considered as stressful medical trauma; and severe athletic injury may produce traumatic-stress reactivity (Appaneal et al., 2007). An athlete's perception and evaluation of a stressful situation determine whether or not he feels negative emotions. This perception and evaluation is referred to as cognitive appraisal (Albinson \& Petrie, 2003; Folkman et al., 1986; Wiese-Bjornstal et al., 1998). The cognitive appraisal of negative events requires the athlete assessing the situation for potential harm and then selecting the appropriate coping resources to deal with it (Tomalski, 2013). Our current research supported that belief and how an athlete views the meaning of his life regulate the way to overcome adverse situations in his sport career, especially those involving injuries and surgeries. Therefore, two different athletes experiencing similar ACL injury and requiring surgery may react in different ways because of their perceptions of the event and personal coping strategies.

The approach coping strategy of using religion was inversely associated with depression, anxiety and stress. In regards to the approach strategy of turning to religion, Kim and Duda (2003) found that athletes tended to use religion as a coping strategy when they undergo psychological stress and that approach coping strategies were considered as more effective in long-term outcomes. Similarly, Tomalski (2013) studied how athletes cope with the anxiety surrounding the possibility of sustaining an injury in the future, he found out that athletes who reported higher scores on using religion tended to have lower anxiety scores related to experiencing pain, loss of social support, and reinjury, possibly because it has been found to be an effective coping strategy.

Religion and/or spirituality provide a source of hope. The belief in an omnipotent God who supports a person through a difficulty can be mentally beneficial and enhance acceptance. In addition, people with high belief often turn outwards towards others for social and emotional support, away from self-reflection and this may have advantageous effects (Dein, 2004).

Therefore, athletes with $\mathrm{PM}^{\mathrm{H}}$ excelled only in term of emotional support. Prayer like meditation can invoke a relaxation response. In addition to the relaxation response, psychological mechanisms that may impact a person's health through prayer may include increased social support, hope or decreased distress. These mechanisms may explain the positive impact of praying for oneself or praying for another in their presence or with their knowledge (Saad \& Medeiros, 2012). 
The standing out of religion/spiritually can be explained by the fact that the belief on itself encourages prayer/meditation but differ in style and technique. Some practice center on ritualistic and sacramental prayer that includes memorized statements to the Divine while others favor spontaneous conversations with God. Regardless of the belief and/or practice, certainly prayer could be an opportunity to communicate with the Divine and it has been found to result in many health benefits including improved psychological functioning and better stress reduction and coping (Krause, 2003, 2004; Masters, 2007).

This study also highlights that RS had stronger association with reduced depression, anxiety and stress when compared to PM.

There are limitations in the current study. The results of this study were based upon professional injured athletes consisting of 50 participants. The grouping of the participants into high and low categories $\left(\mathrm{RS}^{\mathrm{H}}, \mathrm{RS}^{\mathrm{L}}, \mathrm{PM}^{\mathrm{H}}\right.$ and $\left.\mathrm{PM}^{\mathrm{L}}\right)$ should be taken into consideration. These were classified based on two questions of the Brief Cope instrument. It is not possible to distinguish or quantify the levels of religious beliefs and practice based on these items. Therefore these findings should be taken promising to pursue further research on religious beliefs and practice of meditation techniques on injured athletes and the recovery process.

\section{Conclusion}

The results of this study provided evidence that according to the religious beliefs and/or spiritual practice influences negative emotions and coping strategies. More specifically, evidence suggested that professional ACL injured athletes presented different emotions and coping based on their religiousness and spirituality beliefs/practices. Future work in this area needs to look at factors accounting for these associations and mostly needs to be sensitive to theological and cultural dimensions in their assessment. Due to small size of this study, findings should be considered preliminary until large representative studies are performed. Future research among ACL injured athletes should also take an interest in implications of theodicy in mental health and investigate the varieties of religion and spirituality experiences.

\section{References}

Abu-Rayya, H. M., Abu-Rayya, M. H., \& Khalil, M. (2009). The Multi-Religion Identity Measure: A New Scale for Use with Diverse Religions. Journal of Muslim Mental Health, 4, 124-138. https://doi.org/10.1080/15564900903245683

Albinson, C. B., \& Petrie, T. A. (2003). Cognitive Appraisals, Stress, and Coping: Preinjury and Postinjury Factors Influencing Psychological Adjustment to Sport Injury. Journal of Sport Rehabilitation, 12, 306-322. https://doi.org/10.1123/jsr.12.4.306

Antony, M. M., Bieling, P. J., Cox, B. J., Enns, M. W., \& Swinson, R. P. (1998). Psychometric Properties of the 42-Item and 21-Item Versions of the Depression Anxiety Stress Scales in Clinical Groups and a Community Sample. Psychological Assessment, 10, 176. https://doi.org/10.1037/1040-3590.10.2.176

Appaneal, R. N., Perna, F. M., \& Larkin, K. T. (2007). Psychophysiological Response to Severe Sport Injury among Competitive Male Athletes: A Preliminary Investigation. 
Journal of Clinical Sport Psychology, 1, 68-88.

https://doi.org/10.1123/jcsp.1.1.68

Ardern, C. L., Kvist, J., \& Webster, K. E. (2016). Psychological Aspects of Anterior Cruciate Ligament Injuries. Operative Techniques in Sports Medicine, 24, 77-83. https://doi.org/10.1053/j.otsm.2015.09.006

Brown, T. A., Chorpita, B. F., Korotitsch, W., \& Barlow, D. H. (1997). Psychometric Properties of the Depression Anxiety Stress Scales (DASS) in Clinical Samples. Behaviour Research and Therapy, 35, 79-89.

Carver, C. S. (1997). You Want to Measure Coping But Your Protocol' Too Long: Consider the Brief Cope. International Journal of Behavioral Medicine, 4, 92. https://doi.org/10.1207/s15327558ijbm0401_6

Coakley, J., \& Donnelly, P. (2003). Sports and Children. Are Organized Programs Worth the Effort? Sport in Society: Issues \& Controversies.

Dein, S. (2004). Working with Patients with Religious Beliefs. Advances in Psychiatric Treatment, 10, 287-294. https://doi.org/10.1192/apt.10.4.287

Ellison, C. G., Boardman, J. D., Williams, D. R., \& Jackson, J. S. (2001). Religious Involvement, Stress, and Mental Health: Findings from the 1995 Detroit Area Study. Social Forces, 80, 215-249. https://doi.org/10.1353/sof.2001.0063

Ellison, C. G., \& George, L. K. (1994). Religious Involvement, Social Ties, and Social Support in a Southeastern Community. Journal for the Scientific Study of Religion, 46-61. https://doi.org/10.2307/1386636

Everhart, J. S., Best, T. M., \& Flanigan, D. C. (2013). Psychological Predictors of Anterior Cruciate Ligament Reconstruction Outcomes: A Systematic Review. Knee Surgery, Sports Traumatology, Arthroscopy, 23, 752-762. https://doi.org/10.1007/s00167-013-2699-1

Faria, J. B., \& EMF, S. (1997). Pargament KI. The Psychology of Religion and Coping: Theory, Research. Practice. NY: The Guilford.

Folkman, S., Lazarus, R. S., Dunkel-Schetter, C., DeLongis, A., \& Gruen, R. J. (1986). Dynamics of a Stressful Encounter: Cognitive Appraisal, Coping, and Encounter Outcomes. Journal of Personality and Social Psychology, 50, 992. https://doi.org/10.1037/0022-3514.50.5.992

Garbee, D. D., \& Gentry, J. A. (2001). Coping with the Stress of Surgery. AORN Journal, $73,946-951$.

George, L. K., Ellison, C. G., \& Larson, D. B. (2002). Explaining the Relationships between Religious Involvement and Health. Psychological Inquiry, 13, 190-200. https://doi.org/10.1207/S15327965PLI1303_04

Granito Jr, V. J. (2001). Athletic Injury Experience: A Qualitative Focus Group Approach. Journal of Sport Behavior, 24, 63.

Hackney, C. H., \& Sanders, G. S. (2003). Religiosity and Mental Health: A Meta-Analysis of Recent Studies. Journal for the Scientific Study of Religion, 42, 43-55. https://doi.org/10.1111/1468-5906.t01-1-00160

Hoffman, S. J. (1992). Sports and Religion. Champaign: Human Kinetics.

Jona, I. N., \& Okou, F. T. (2013). Sports and Religion. Religion, 2.

Joseph, E. (2012). The Multi-Dimensional Relationship between Religion and Sport. Journal of Physical Education and Sport Management, 3, 1-7.

Joshi, S., Kumari, S., \& Jain, M. (2008). Religious Belief and Its Relation to Psychological Well-Being. Journal of the Indian Academy of Applied Psychology, 34, 345-354.

Kim, M. S., \& Duda, J. L. (2003). The Coping Process: Cognitive Appraisals of Stress, 
Coping Strategies, and Coping Effectiveness. The Sport Psychologist, 17, 406-425. https://doi.org/10.1123/tsp.17.4.406

Koenig, H. G., McCullough, M. E., \& Larson, D. B. (2001). Handbook of Religion and Health. Oxford: Oxford University Press. https://doi.org/10.1093/acprof:oso/9780195118667.001.0001

Krägeloh, C. U. (2011). A Systematic Review of Studies Using the Brief COPE: Religious Coping in Factor Analyses. Religions, 2, 216-246. https://doi.org/10.3390/rel2030216

Krause, N. (2004). Assessing the Relationships among Prayer Expectancies, Race, and Self-Esteem in Late Life. Journal for the Scientific Study of Religion, 43, 395-408. https://doi.org/10.1111/j.1468-5906.2004.00242.x

Krause, N. (2003). Praying for Others, Financial Strain, and Physical Health Status in Late Life. Journal for the Scientific Study of Religion, 377-391. https://doi.org/10.1111/1468-5906.00189

Lane, K. (2014). Cossacks, Holy Bread, Running Shorts and Energy Gels, the Race for Religion in Modern Societies.

Masters, K. S. (2007). Prayer and Health. In C. E. Thoresen, \& T. G. Plante (Eds.), Spirit, Science, and Health: How the Spiritual Mind Fuels Physical Wellness (pp. 11-24). Westport, CT: Praeger.

Nawel, H., \& Elisabeth, S. (2015). Adaptation and Validation of the Tunisian Version of the Brief COPE Scale. European Health Psychologist, 17, 783.

Peres, J. F. H., Moreira-Almeida, A., Nasello, A. G., \& Koenig, H. G. (2007). Spirituality and Resilience in Trauma Victims. Journal of Religion and Health, 46, 343-350. https://doi.org/10.1007/s10943-006-9103-0

Saad, M., \& de Medeiros, R. (2012). Spiritual-Religious Coping-Health Services Empowering Patients' Resources. Rijeka: INTECH Open Access Publisher. https://doi.org/10.5772/50443

Sarkar, M., Hill, D. M., \& Parker, A. (2015). Reprint of: Working with Religious and Spiritual Athletes: Ethical Considerations for Sport Psychologists. Psychology of Sport and Exercise, 17, 48-55.

Smith, T. B., McCullough, M. E., \& Poll, J. (2003). Religiousness and Depression: Evidence for a Main Effect and the Moderating Influence of Stressful Life Events. Psychological Bulletin, 129, 614. https://doi.org/10.1037/0033-2909.129.4.614

Stevenson, C. L. (1991). The Christian-Athlete: An Interactionist-Developmental Analysis. Sociology of Sport Journal, 8, 362-379. https://doi.org/10.1123/ssj.8.4.362

Tomalski, J. L. (2013). The Relationship between Coping and Sport Injury Anxiety among College Athletes. Doctoral Dissertation, Greensboro: The University of North Carolina.

Wiese-Bjornstal, D. M., Smith, A. M., Shaffer, S. M., \& Morrey, M. A. (1998). An Integrated Model of Response to Sport Injury: Psychological and Sociological Dynamics. Journal of Applied Sport Psychology, 10, 46-69

Williams, D. R., \& Sternthal, M. J. (2007). Spirituality, Religion and Health: Evidence and Research Directions. Medical Journal of Australia, 186, S47. 
Submit or recommend next manuscript to SCIRP and we will provide best service for you:

Accepting pre-submission inquiries through Email, Facebook, LinkedIn, Twitter, etc. A wide selection of journals (inclusive of 9 subjects, more than 200 journals)

Providing 24-hour high-quality service

User-friendly online submission system

Fair and swift peer-review system

Efficient typesetting and proofreading procedure

Display of the result of downloads and visits, as well as the number of cited articles Maximum dissemination of your research work

Submit your manuscript at: http://papersubmission.scirp.org/

Or contact ape@scirp.org 